\title{
Sleep Hours: Risk behavior in adolescents from different countries
}

\author{
Horas de sono: comportamento de risco em adolescentes de \\ diferentes países
}

Silvia Bandeira da Silva Lima (https://orcid.org/0000-0002-6862-2944) ${ }^{1}$
Walcir Ferreira-Lima (https://orcid.org/0000-0003-0932-7969) ${ }^{1}$
Flávia Évelin Bandeira Lima (https://orcid.org/0000-0002-7026-3354) ${ }^{2}$
Fellipe Bandeira Lima (https://orcid.org/0000-0001-5917-6412) ${ }^{3}$
Amanda Santos (http://orcid.org/0000-0003-2866-846X) ${ }^{4}$
Carlos Alexandre Molena Fernandes (https://orcid.org/0000-0002-4019-8379) ${ }^{5}$
Juan Pedro Fuentes (https://orcid.org/0000-0002-8299-1092) ${ }^{1}$

${ }^{1}$ Facultad de Ciencias del Deporte, Universidad de Extremadura. Av. De la Universidad, Campus Universitario s/n. 10003 Cáceres Espanha.

silviabslima@hotmail.com

${ }^{2}$ Universidad de

Extremadura. Badajoz Espanha.

${ }^{3}$ Universidade Estadual do Norte do Paraná.

Jacarezinho PR Brasil.

${ }^{4}$ Faculdade de Desporto,

Universidade do Porto.

Porto Portugal.

${ }^{5}$ Departamento de

Educação Física,

Universidade Estadual

do Paraná. Paranavaí PR

Brasil.

\begin{abstract}
The aim of this study was to verify sleep hours and associated factors among Brazilian and Spanish students. A cross-sectional study with students aged 11 to 16 years-old was carried out in Paranavaí, Brasil $(n=264)$ and Cáceres, Spain $(n=233)$ between 2013 and 2015. Sleeping hours were verified regarding time in minutes, sleep in weekdays, weekends and after lunch/Siesta. All data were checked for normality by the Kolmogorov-Smirnov test. Mann-Whitney U test, Chisquare test $\left(X^{2}\right)$ and Odds Ratio estimates were used $(p<0.05)$. High prevalence in both groups of sleeping 8 hours or more a night at the weekend. The prevalence of sleeping on weekdays, $>8$ hours, 6 to 8 hours and $<6$ hours among Spanish and Brazilian students, respectively. Nearly a quarter of each group responded that makes the siesta. Spanish students had 3 times higher chance to sleep $<8$ hours a night in weekdays, among students from 14 to 16 years old and among the underactive. At the weekends the chance of sleeping $<8$ hours is 2 times greater among the Spanish students. Simple guidelines could help so that sleep habits do not affect school development, such as practicing physical activity regularly, sleeping at least 8 hours a night, avoid excessive access to technology at night.

Key words Sleep, Adolescents, Risk-taking
\end{abstract}

Resumo $O$ objetivo deste estudo foi verificar as horas de sono e fatores associados em estudantes brasileiros e espanhóis. Foi realizado um estudo transversal com estudantes de 11 a 16 anos de idade em Paranavaí, Brasil $(n=264)$ e Cáceres, Espanha $(n=233)$ entre 2013 e 2015. As horas de sono foram verificadas em relação ao tempo em minutos, dias da semana, fins de semana e Siesta. Todos os dados foram verificados quanto à normalidade pelo teste de Kolmogorov-Smirnov. Os testes de Mann-Whitney, Qui-quadrado $\left(X^{2}\right)$ e a estimativa do Odds Ratio foram utilizados $(p<0,05)$. Entre os espanhóis e os brasileiros, as prevalências de dormir em dias de semana foram $>8$ horas, 6 a 8 horas e $<6$ horas, respectivamente. Quase um quarto em cada grupo respondeu fazer a Siesta. Os espanhóis apresentaram 3 vezes mais chance de dormir menos de 8 horas por noite durante a semana, entre os de 14 a 16 anos e pouco ativos. Aos finais de semana, a chance de dormir menos de 8 horas foi duas vezes maior entre os espanhois. Orientações simples podem ajudar, para que os hábitos de sono não afetem o desenvolvimento escolar, como praticar atividade física regularmente, dormir pelo menos 8 horas por noite, evitar o acesso excessivo de tecnologia durante a noite.

Palavras-chave Sono, Adolescentes, Comportamento de risco 


\section{Introduction}

Sleep is defined as the suspension of normal consciousness, which consumes a third of our life ${ }^{1}$. Good sleep is considered to be closely related to age and neurodevelopment ${ }^{2}$. The quality of the sleep depends on besides maintaining it for a few hours, in also producing neurovegetative activities, of vital importance for the repair and maintenance of the organism and as a consequence, to facilitate the behavior and the good performance of the diurnal activities ${ }^{3}$.

Therefore, sleep problems present in children and adolescents will have a negative impact on the development of physiological function and cognitive performance, which may affect the dynamics and quality of family life ${ }^{1}$. It is estimated that more than $30 \%$ of children and adolescents in the world present with sleep disorders, such as: insomnia, nocturnal awakenings, restless legs syndrome, somnambulism, speech during sleep, bruxism and delayed sleep phase, that somehow, will affect the time spent in bed ${ }^{4}$.

Research indicates that in addition to these disorders, most adolescents sleep around 7 hours a night, approximately one hour less than their estimated need for sleep 5 . This reduction in sleep would be linked to increased social demands, insertion in the work world, school activities, hormonal changes that alter the circadian rhythm and an excessive use of electronic equipment ${ }^{6}$. Another study found that about $40 \%$ of adolescents who have short sleep, have reported waking up tired, this fatigue causes increased daytime sleepiness, which would be a consequence of sleep deprivation due to school hours and may influence cognitive performance ${ }^{7}$.

A meta-analysis of protective and risk factors for sleep in 85.561 adolescents aged 12 to 18 yearsold showed that good sleep hygiene and physical activity were associated with earlier bedtime and longer sleep time ${ }^{8}$. In addition to the impact on cognitive functions caused by the partial or continuous reduction of sleep, hormonal effects such as elevated nocturnal cortisol, increased sympathetic nervous system activity and decreased thyroid stimulating hormone ${ }^{9}$. As a consequence, it cause an increase in the production of ghrelin (hormone that increases the appetite) and leptin decrease (hormone that reduces the appetite) occurs, consequently, these hormonal changes can contribute to increase obesity and hypertension?.

As a consequence of this, an association with increases in body fat was identified; greater participation in sedentary leisure activities, such as: watching TV, using computer and playing video game; low physical activity level; high-fat foods and carbohydrates consumption ${ }^{10}$. A study with Saudi adolescents aged 15 to 19 showed that short sleep duration $(<8 \mathrm{~h} /$ day $)$ was significantly associated with several lifestyle factors ${ }^{11}$. Therefore, it is considered that sleep can influence the behavioral and emotional state, physical and cognitive development, as well as adolescents attention and learning levels. In general, it is noted that poor sleep habits, initiated in childhood and adolescence, can accompany the person in adult life ${ }^{4}$.

In this way, understanding this risk behavior, the prevalence and associated factors that influence lifestyle, is a challenge, because when you study adolescents, the influences on their behavior change and even more complexity is added to this phenomenon, with variables such as gender, ethnicity, socioeconomic status and cultural differences ${ }^{12}$. According to Knutson ${ }^{7}$, although the literature points out that there were no significant differences in sleep duration between the genders on weekdays and on weekends, there may be differences between genders, in the association between puberty and sleep problems due to biological maturation and physiology of puberty that varies greatly between the genders and individuals. Thus, the aim of this study was to verify sleep hours and associated factors among Brazilian and Spanish students.

\section{Methods}

A cross-sectional and observational study carried out in schools in the cities of Cáceres-Extremadura-Spain (SPA-G) in 2015, located in the center of the Autonomous Community of Extremadura, has 95.855 inhabitants, with a Human Development Index (HDI) of 0,872 , similar to the Spanish HDI of $0,876^{13}$ and Paranavaí-Paraná-Brazil (BRA-G) in 2013, located in the northwestern part of the state of Paraná, in southern Brazil, with 81.595 inhabitants, and a Human Development Index (HDI) of 0,725, similar to the HDI of Brazil of $0.744^{14}$.

The intervention protocols in the study were authorized in Spain by the Comision de Bioética y Bioseguridad de La Universidad de Extremadura, and in Brazil for Comitê de Ética em Pesquisa Envolvendo Seres Humanos da Universidade Estadual de Maringá.

Systematic random sampling was conducted in four stages: 1) draw of one school from each region of the city; 2) classes draw in each school; 
3) invitation to all the students of the classes drawn, and explanations about the study; 4) delivery of the Informed Consent Form for the signature of the parents or guardians of the minor.

In Spain, the sample was composed of students from $1^{\text {st }}$ to $3^{\text {rd }}$ year of compulsory secondary education, enrolled in four public schools and two private schools, from a total of 23 public schools and 11 private schools in the municipality. The information used for the sample calculation was obtained from the Ministry of Education, Culture and Sport of Spain (Facts and Figures - School year 2014/2015) and considering the student population in Cáceres $(\mathrm{N}=$ 5.817 ); confidence level of $95 \%$; tolerable error of $5 \%$ and the estimated prevalence for Sleep Hours of $50 \%$. The minimum sample calculated was $\mathrm{n}$ $=190,10 \%$ were added to the sample, predicting eventual losses and refusals and $10 \%$ for the multivariate analyzes, and the result was a $\mathrm{n}=$ 233 sample who completed the anthropometric and hemodynamic evaluations, in addition to responding to the questionnaire, respectively.

In Brazil, the sample was composed of students from the $6^{\text {th }}$ grade of elementary school to the $1^{\text {st }}$ year of high school enrolled in four public schools and two private schools, from a total of 18 public schools and 9 private schools in the municipality. The information used for the sample calculation was obtained from the Education Center from the Region of Paranavaí, Paraná, Brazil - 2013 and the student population in $\mathrm{Pa}$ ranavaí $(\mathrm{N}=4.540)$; confidence level of $95 \%$; tolerable error of $5 \%$ and the estimated prevalence for Sleep Hours of $50 \%$. The minimum sample calculated was $\mathrm{n}=188$. The same increases mentioned above were followed for the Spanish sample, totaling a final sample of $\mathrm{n}=264$.

Sleeping hours were verified with information about the time (in minutes) spent sleeping on weekdays and weekends, divided into three categories: $>8$ hours, from 6 to 8 hours and $<6$ hours (sleep in weekdays and weekend), according to the minimum recommendations (8 hours) of the National Sleep Foundation ${ }^{15}$. As well as Sleep after lunch/Siesta: No, Yes; How many minutes of Siesta: none, 0 to 60 minutes, $>60 \mathrm{~min}$ utes.

The variables considered for exposure were: gender (female/male); age (11 to 13 and 14 to 16 years old); administrative dependency of the school (private/public); weight excess (overweight and obesity)/normal (BMI); abdominal/ normal waist circunference (WC); physical activity level (low active/active) (PAL) and systolic (SBP) and diastolic (DBP) blood pressure.

Stature was measured three times, standing with a reading accuracy of $0,01 \mathrm{~m}$ and body mass with an accuracy of up to 100 grams, per researcher trained following the procedures ${ }^{16}$. BMI was calculated by considering the ratio of body mass in kilograms to the square of height in meters $\left(\mathrm{kg} / \mathrm{m}^{2}\right)$, according to age and sex adjusted cutoff points ${ }^{17}$.

WC was measured by means of an inextensible tape measure, half the distance between the iliac crest and the last rib in duplicates, averaging and assuming a maximum variation of $0,5 \mathrm{~cm}$ between the two and repeating the procedure if it exceeds this variation (accuracy of $0,1 \mathrm{~cm}$ ). The students were classified as non-obese and obese according to the cutoff adjusted for sex and age ${ }^{18}$.

The PAL was evaluated by means of the International Physical Activity Questionnaire (International Physical Activity Questionnaire - IPAQ-A) modified for adolescents ${ }^{19}$, taking as reference the last week (underactive $<300 \mathrm{~min} /$ week $)^{20}$.

The levels of SBP and DBP were measured in the right arm of each individual after five minutes of rest, seated, protocol validated for students $^{21}$. The measurements were measured using an electronic and digital oscillometric device with inflation and automatic deflation of the OMRON brand, model HEM-742. Individuals who presented systolic and/or diastolic blood pressure values in the $\geq 95$ percentile $^{22}$, for sex and age, adjusted for the percentile of height ${ }^{23}$, were considered with high blood pressure.

All data were checked for normality by the Kolmogorov-Smirnov test. Descriptive data were shown in mean, standard deviation, median, absolute and relative frequency. The Mann-Whitney $U$ test was used to compare the numerical variables between BRA-G and SPA-G. The categorical variables (frequency proportion according to cut-off points considered) were analyzed using cross-tables, involving Chi-square test $\left(\mathrm{X}^{2}\right)$, Cramer V and Phi tests, to identify statistical differences between groups (multiple adjusted comparisons by the Bonferroni method). Odds Ratio (OR) estimates, with a 95\% confidence interval, were performed to analyze the associations between the variables. All statistics analyses were performed using SPSS software, version 24.0, and the significance level was set at $p<0.05$. 


\section{Results}

The sample was composed in Cáceres by 233 students, with the highest participation in the category of 14 to 16 years $(72,1 \%)$, the majority of males $(53,2 \%)$, from public/concerted school (receives funding from Spain government) $(56,2 \%)$. While in Paranavaí, 264 students participated, with the largest participation in the category of 14 to 16 years $(54,2 \%)$, the majority of females (54,9\%), from public schools $(62,9 \%)$.

Table 1 Sample descriptive characteristics and comparison between SPA-G (2015) and BRA-G (2013). There was significant difference for age, BMI, WC, PAL, DBP between SPA-G (2015) and BRA-G. Table 2 presents the proportions comparisons of the variables variables included in the study between SPA-G (2015) and BRA-G (2013). The results showed that the SPA-G were significantly older $(\mathrm{p}=0.001)$ and appeared to sleep significantly more hours during the weekdays $(\mathrm{p}=0.018)$ compared to the BRA-G. Regarding to sleep duration, the prevalence was high in both groups, of which they reported sleeping 8 hours or more a night at the weekend. However, this prevalence decreased considerably during the week, only $26,1 \%$ of Spanish and $33,7 \%$ of Brazilians sleep 8 hours or more, the rest of the sample sleeps from 6 to 8 hours $(73,0 \%$ vs $44,7 \%)$, and less than 6 hours $(0,9 \%$ vs $21,6 \%)$, between Spanish and Brazilian, respectively. Nearly a quarter of each group responded that makes the siesta after lunch. The proportions were not different for BMI, PAL and BP, between the two groups. Although not showing statistically significant proportions, what is striking is the high prevalence, for example, SPA-G $(51,9 \%)$ and BRA-G $(58,0 \%)$ are insufficiently active, and SPA-G (24\%) and BRA-G $(23,9 \%)$ presented altered blood pressure.

Table 3 shows results regarding Odds $R a$ tio (OR) and confidence interval (95\% CI) of sleep hours. The chance of sleeping less than 8 hours per night in SPA-G was approximately 3 times higher among students 14 to 16 yearsold compared to 11 to 13 years-old (Age: OR = $3.096(1.663-5.762) ; \mathrm{p}=0.001)$ and among the less active compared to more active (PAL: OR = 3.114 (1.669-5.808); $\mathrm{p}=0.001)$. At the weekends the chance of sleeping less than 8 hours was approximately 2 times higher among Spanish boys compared to Spanish girls (Gender: $\mathrm{OR}=2.378$ (1.233-4.587); $\mathrm{p}=0.010)$. There were no significant associations for BRA-G.

\section{Discussion}

The present study proposed to verify the hours of sleep between the students of the two mentioned countries. The results showed that the prevalence were not statistically significant, although the two groups had high prevalence rates for sleeping 8 hours or more per night at the weekend, these prevalences dropped considerably during the week. Practically three quarters of the two groups sleep between 6 and 8 hours, or less than 6 hours a night, during the week. The hypothesis that may be involved in this result refers to the daily social and behavioral habits of the students being similar, even in populations with different customs and cultures.

Table 1. Sample descriptive characteristics and comparison between SPA-G (2015) and BRA-G (2013).

\begin{tabular}{|c|c|c|c|c|c|c|c|c|}
\hline & \multicolumn{3}{|c|}{ SPA-G $(n=233)$} & \multicolumn{3}{|c|}{ BRA-G $(n=264)$} & \multirow{2}{*}{$\mathrm{U}$ - test } & \multirow{2}{*}{ p-value } \\
\hline & mean \pm sd & median & $(\min -\max )$ & eean \pm sd & median & $(\min -\max )$ & & \\
\hline Age (years) & $14.2 \pm 1.1$ & 14.3 & $(11.3-16.4)$ & $13.7 \pm 1.7$ & 13.8 & $(10.6-16.4)$ & 25457.0 & 0.001 \\
\hline $\mathrm{BMI}(\mathrm{Kg} / \mathrm{m} 2)$ & $21.0 \pm 3.3$ & 20.3 & $(13.5-33.2)$ & $20.4 \pm 3.8$ & 9.8 & $-36.4)$ & 26723.0 & 0.012 \\
\hline $\mathrm{WC}(\mathrm{cm})$ & $68.2 \pm 8.0$ & 66.5 & $(52.0-105.0)$ & $73.8 \pm 10.7$ & 72.0 & $(41.1-109.0)$ & 41353.5 & 0.001 \\
\hline PAL ( $\mathrm{min} /$ & $417.5 \pm 396.2$ & 270.0 & $(20.0-2310.0)$ & $350.3 \pm 318.4$ & 240.0 & $(15.0-1470.0)$ & 27356.0 & 0.033 \\
\hline $\mathrm{SBP}(\mathrm{mmHg})$ & $112.6 \pm 14.0$ & 112.3 & $(75.0-151.5)$ & $110.3 \pm 15.0$ & 110.0 & $(68.0-152.0)$ & 28083.0 & 0.094 \\
\hline DBP (mmHg) & $64.6 \pm 9.5$ & 63.5 & $(46.0-111.0)$ & $67.0 \pm 12.0$ & 67.0 & $(40.0-103.0)$ & 35138.5 & 0.006 \\
\hline \multicolumn{9}{|l|}{ Sleep } \\
\hline Weekend (hrs) & $9.4 \pm 1.6$ & 10.0 & $(4.0-14.0)$ & $9.6 \pm 2.1$ & 9.0 & $(4.0-16.0)$ & 30599.5 & 0.921 \\
\hline Weekdays (hrs) & $7.9 \pm 1.0$ & 8.0 & $(3.5-12.0)$ & $7.9 \pm 2.0$ & 8.0 & $(4.0-14.0)$ & 30396.5 & 0.819 \\
\hline Siesta (min) & $13.9 \pm 37.1$ & 0.0 & $(0.0-300.0)$ & $23.4 \pm 51.5$ & 0.0 & $(0.0-300.0)$ & 32603.0 & 0.110 \\
\hline
\end{tabular}

BMI: Body Mass Index; WC: Waist Circumference; PAL: Physical Activity Level; SBP: Systolic Blood Pressure; DBP: Diastolic Blood Pressure; cm: centimeters; min/wk: minutes/week; hrs: hours; sd: standard deviation; min-max: minimum-maximum; U: MannWhitney U test. 
Table 2. Comparing the proportions of the variables between SPA-G (2015) and BRA-G (2013).

\begin{tabular}{|c|c|c|c|c|c|c|}
\hline & \multicolumn{2}{|c|}{ SPA-G $(n=233)$} & \multicolumn{2}{|c|}{ BRA-G $(n=264)$} & \multirow{2}{*}{$\mathrm{X}^{2}$ test } & \multirow{2}{*}{ p-value } \\
\hline & $\mathrm{f}$ & $(\%)$ & $\mathbf{f}$ & $(\%)$ & & \\
\hline Age & & & & & & 0.001 \\
\hline 11 to 13 & 65 & 27.9 & 121 & 45.8 & 17.002 & \\
\hline 14 to 16 & 168 & 72.1 & 143 & 54.2 & & \\
\hline Gender & & & & & & 0.070 \\
\hline Girls & 109 & 46.8 & 145 & 54.9 & 3.284 & \\
\hline Boys & 124 & 53.2 & 119 & 45.1 & & \\
\hline $\mathrm{AD}$ & & & & & & 0.131 \\
\hline Public & 131 & 56.2 & 166 & 62.9 & 2.280 & \\
\hline Private & 102 & 43.8 & 98 & 37.1 & & \\
\hline BMI & & & & & & 0.818 \\
\hline Normal & 177 & 76 & 202 & 76.5 & 0.053 & \\
\hline Overweight & 45 & 19.3 & 45 & 17 & & \\
\hline Obesity & 11 & 4.7 & 17 & 6.4 & & \\
\hline WC (age; gender) & & & & & & 0.512 \\
\hline Normal & 188 & 80.7 & 219 & 83.0 & 0.429 & \\
\hline Abnormal & 45 & 19.3 & 45 & 17.0 & & \\
\hline $\operatorname{PAL}(<300 \mathrm{~min} / \mathrm{wk})$ & & & & & & 0.178 \\
\hline Active & 111 & 48.1 & 111 & 42.0 & 1.815 & \\
\hline Underactive & 120 & 51.9 & 153 & 58.0 & & \\
\hline $\mathrm{BP}$ & & & & & & 0.965 \\
\hline Normal & 177 & 76 & 201 & 76.1 & 0.002 & \\
\hline Abnormal & 56 & 24 & 63 & 23.9 & & \\
\hline Sleep - weekend & & & & & & 0.079 \\
\hline$>8$ hours & 181 & 77.7 & 186 & 70.5 & 3.085 & \\
\hline 6 to 8 hours & 48 & 20.6 & 72 & 27.3 & & \\
\hline$<6$ hours & 4 & 1.7 & 6 & 2.3 & & \\
\hline Sleep - weekdays & & & & & & 0.018 \\
\hline$>8$ hours & 61 & 26.2 & 89 & 33.7 & 5.562 & \\
\hline 6 to 8 hours & 170 & 73 & 118 & 44.7 & & \\
\hline$<6$ hours & 2 & 0.9 & 57 & 21.6 & & \\
\hline Sleep after lunch & & & & & & 0.185 \\
\hline No & 188 & 80.7 & 200 & 75.8 & 1.756 & \\
\hline Yes & 45 & 19.3 & 64 & 24.2 & & \\
\hline Quantos Min. Siesta & & & & & & 0.052 \\
\hline None & 188 & 80.7 & 200 & 75.8 & 3.767 & \\
\hline 0 to $60 \mathrm{~min}$. & 31 & 13.3 & 32 & 12.1 & & \\
\hline$>60 \mathrm{~min}$. & 14 & 6.0 & 32 & 12.1 & & \\
\hline
\end{tabular}

Many adolescents develop irregular sleep patterns, sleeping a few hours during school days, and more hours at the weekend to partially compensate for sleep deprivation during the week ${ }^{24}$. According to some authors, it was found that on weekends and holidays, adolescents sleep and wake up later, in addition to sleeping longer. This can be explained as a consequence of the fact that adolescents during the week are usually involved in studies and/or work activities, especially in the morning, associated with the habit of attending social networks on the internet for longer, during the night ${ }^{25}$.

The SPA-G of 14 to 16 years presented more chance of sleeping less than 8 hours per night during the week, compared to their younger pairs 
Table 3. Odds ratio (OR) of sleep hours on weekdays and weekends, according to anthropometric, sociodemographic and behavioral characteristics, SPA-G (2015) and G-BRA (2013).

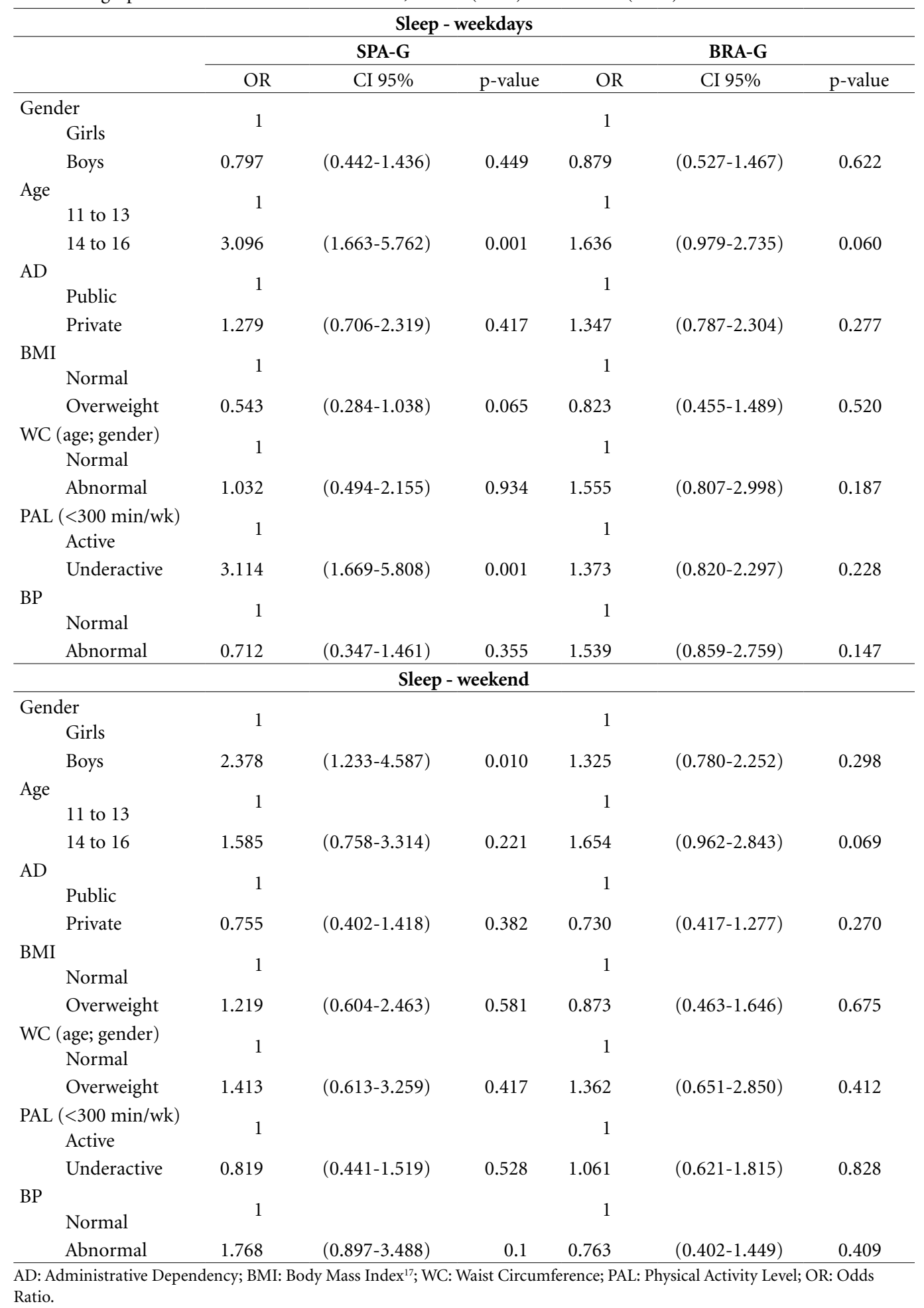

and among the less active ones. Some authors affirm that the quality and duration of sleep of ac- tive people is better than that of inactive people, this hypothesis could be explained by the fact that 
good nights of sleep would provide less fatigue during the day and more disposition to practice physical activity ${ }^{3}$. Conversely, in another study it was observed that the proportion of overweight and obese adolescents was higher among those who had a negative perception of sleep quality and insufficient physical activity level ${ }^{26}$.

At the weekend the chance of sleeping less than 8 hours is greater among Spanish boys. A possible cause of the difference between the sexes may be related to hormonal changes due to pubertal maturation ${ }^{27}$. The literature shows that adolescents need sufficient sleep to function well daily, good sleep habits contribute to the physical and intellectual improvement of the body, important factors for the optimization of cognitive performance in daily activities, propitiating, the enhancement of learning ability in school ${ }^{8}$.

With the use of accelerometers, research shows that the time spent in sedentary behaviors was significantly higher among those who slept less than in adolescents who slept at least 8 hours a night ${ }^{27}$. Short sleep time was associated with poor learning outcomes, various addictions, an increased risk of obesity and diabetes, and more frequent signs of anxiety and depression ${ }^{28}$. In agreement with this information, the results of a survey show that the average sleep duration was $6,93( \pm 1,24)$ hours for adolescents 13 to 18 years of age. Of this sample, $86,2 \%$ used the computer before bed. Above all, it has been observed that one in three teenagers feels drowsy at school ${ }^{29}$.

Regarding sleeping after lunch, or doing "la siesta”, practically a quarter of the students in both groups answered that they have this habit. Studies on the health effects of naps after lunch are still controversial. Overall, there is some consensus that small asleep $(<20-30$ minutes $)$ may increase attention and improve cognitive performance without negatively affecting nighttime sleep. A meta-analysis with 98.163 people concluded that there is an association between people who nap and a small increase in mortality with an incidence of various diseases. But this association would be for people who sleep more than 60 minutes $^{30}$.

However, the existence of an association between siesta and certain diseases, or increased mortality does not imply a cause-and-effect relationship. One explanation is that individu- als with nocturnal sleep disorders, such as obstructive sleep apnea, diabetes, hypertension, or depression, would experience greater daytime sleepiness and make naps longer and more frequent than healthy individuals ${ }^{24}$. In the case of adolescents practicing siesta, the literature shows that the duration of nocturnal sleep decreases in this phase, increasing the incidence of daytime sleepiness, since the decrease in the duration of sleep in this phase of life does not correspond to a decrease in the need for sleep, but reflects a sleep $\operatorname{debt}^{30}$.

Given the influence of students' sleep habits on physical and mental well-being, the objective of this part of the research was to verify the sleep hours of both samples. The data show that sleep habits and the period of study are probably interrelated and may influence the cognitive performance of the school and the behavioral leisure activities of these adolescents. Therefore, the need to structure simple strategies to solve, in part, this problem, for example, the development of pedagogical activities aiming to sensitize and guide students about the importance of sleep and the maintenance of appropriate attitudes. And even more complex attitudes such as delaying in one or two hours, the beginning of classes, which would result in an increase in total nighttime sleep time in this age group.

The present study presents limitations, as the transverse conception of the data does not provide evidence for causes, only the presence or absence of associations and the exposures and results were based on self-report, bias prone. Regarding to the hours of sleep, in general, more than half of the sample presented that sleep less than the necessary hours recommended for this age group. This is troubling as has been demonstrated from the discussion, both excess and sleep deprivation are detrimental to the metabolic, endocrine and immune system. A part of the students had the habit of doing the siesta, which if not exaggerated serves as a restful sleep for the nocturnal sleep deficit. As important as other risk behaviors, sleep habits should be oriented so that they do not primarily hamper school development. Simple guidelines can help, such as practicing physical activity regularly, sleeping at least 8 hours a night, avoiding excessive access to technology especially at night. 


\section{Collaborations}

All authors contributed significantly and are in agreement with the content of the manuscript.

\section{Acknowledgements}

Thanks to the Coordenação de Aperfeiçoamento de Pessoal em Nível Superior (CAPES) - Brazil, for the scholarship awarded Full Doctoral Degree - Science without Borders, and to Centro de Investigação em Actividade Física, Saúde e Lazer (CIAFEL) of the University of Porto - Portugal, for international academic internship.

\section{References}

1. Andreu MM, Arboledas GP. Trastornos del sueño durante la adolescencia. Rev Formación Continuada Sociedad Española Med Adolescencia 2013; 3(I):29-66.

2. Martínez-Gómez D, Ruiz JR, Gómez-Martínez S, Chillón P, Rey-López JP, Díaz LE, Castillo R, Veiga OL, Marcos A, AVENA Study Group. Active commuting to school and cognitive performance in adolescents: the AVENA study. Arch Pediatr Adolesc Med 2011; 165(4):300-305.

3. Sequeida J, Ortiz M. Sueño en escolares y adolescentes, su importancia y promoción a través de programas educativos: Education and behavioral approach programs. Rev Chilena Pediatr 2013; 84:554-564.

4. Felden ÉPG, Leite CR, Rebelatto CF, Andrade RD, Beltrame TS. Sono em adolescentes de diferentes níveis socioeconômicos: revisão sistemática. Rev Paulista Pediatr 2015; 33(4):467-473.

5. Matricciani L, Olds T, Petkov J. In search of lost sleep: secular trends in the sleep time of school-aged children and adolescents. Sleep Med Rev 2012; 16(3):203211.

6. Calamaro CJ, Mason TB, Ratcliffe SJ. Adolescents living the 24/7 lifestyle: effects of caffeine and technology on sleep duration and daytime functioning. Pediatrics 2009; 123:e1005-e10.

7. Knutson KL. The association between pubertal status and sleep duration and quality among a nationally representative sample of US adolescents. Am J Hum Biol 2005; 17(4):418-424.

8. Bartel KA, Gradisar M, Williamson P. Protective and risk factors for adolescent sleep: a meta-analytic review. Sleep Med Rev 2015; 21:72-85.

9. Fatima Y, Mamun A. Longitudinal impact of sleep on overweight and obesity in children and adolescents: a systematic review and bias-adjusted meta-analysis. Obes Rev 2015; 16(2):137-149.

10. Silva ML, Magalhães AA. Duração do sono, sobrepeso e obesidade na adolescência: uma revisão sistemática. MTP Rehab J 2014; 12:231-236.

11. Al-Hazzaa H, Musaiger A, Abahussain N, Al-Sobayel HI, Qahwaji DM. Lifestyle correlates of self-reported sleep duration among Saudi adolescents: a multicentre school-based cross-sectional study. Child Care Health Dev 2014; 40(4):533-542.

12. Mota J, Sallis JF. Actividade fisica e saúde: Factores de influência da actividade física nas crianças e nos adolescentes. Porto: Ed. Campo das Letras; 2002.

13. Cáceres WodEAd. Ayuntamiento de Cáceres. 2017.

14. Instituto Brasileiro de Geografia e Estatística (IBGE). Pesquisa Nacional de Saúde do Escolar (PeNSE) 2012. Rio de Janeiro: IBGE; 2013. 
15. Hiestand DM, Britz P, Goldman M, Phillips B. Prevalence of symptoms and risk of sleep apnea in the US population: results from the national sleep foundation sleep in America 2005 poll. Chest 2006; 130(3):780-786.

16. Lohman TG, Roche AF, Martorell R. Anthropometric standardization reference manual. Champaign: Human kinetics books; 1988.

17. Cole TJ, Bellizzi MC, Flegal KM, Dietz WH. Establishing a standard definition for child overweight and obesity worldwide: international survey. BMJ 2000; 320(7244):1240-1243.

18. Taylor RW, Jones IE, Williams SM, Goulding A. Evaluation of waist circumference, waist-to-hip ratio, and the conicity index as screening tools for high trunk fat mass, as measured by dual-energy $\mathrm{X}$-ray absorptiometry, in children aged 3-19 y. Am J Clin Nutri 2000; 72(2):490-495.

19. Arvidsson D, Slinde F, Hulthèn L. Physical activity questionnaire for adolescents validated against doubly labelled water. Eur J Clin Nutr 2005; 59(3):376-383.

20. Strong WB, Malina RM, Blimkie CJ, Daniels SR, Dishman RK, Gutin B, Hergenroeder AC, Must A, Nixon PA, Pivarnik JM, Rowland T, Trost S, Trudeau F. Evidence based physical activity for school-age youth. $J$ Pediatr 2005; 146(6):732-737.

21. Christofaro DGD, Casonatto J, Polito MD, Cardoso JR, Fernandes R, Guariglia DA, Gerage AM, Oliveira AR. Evaluation of the Omron MX3 Plus monitor for blood pressure measurement in adolescents. Eur J Pediatr 2009; 168(11):1349-1354.

22. Sociedade BdH-S, Cardiologia SBd, Nefrologia SBd.V Brazilian Guidelines in Arterial Hypertension. Arqui Brasileiros Cardiol 2007; 89:e24.

23. Kuczmarski RJ, Ogden CL, Grummer-Strawn LM, Flegal KM, Guo SS, Wei R, Mei Z, Curtin LR, Roche AF, Johnson CL. CDC growth charts: United States. Adv Data 2000; 314:1-27.

24. Andréu MM, Larrinaga AÁR, Pérez JAM, Martínez MAM, Cuesta FJP, Guerra AJA, Santo-Tomás OR, Luque MJJ, Isern FJS, Sanz TC, Rodríguez PG, Santos JT, Álvarez MLA, Díaz-Varela DG-B, Esteban BB. Sueño saludable: evidencias y guías de actuación. Documento oficial de la Sociedad Española de Sueño. Rev Neurol 2016; 63(Supl. 2):S1-S27.

25. Rombaldi AJ, Soares DG. Indicadores da prática de atividade física e da qualidade do sono em escolares adolescentes. Rev Bras Cien Esporte 2016; 38(3):290296.
26. Petribú MMV, Tassitano RM, Nascimento WMF, Santos EMC, Cabral PC. Factors associated with overweight and obesity among public high school students of the city of Caruaru, Northeast Brazil. Rev Paulista Pediatr 2011; 29(4):536-545.

27. Garaulet M, Ortega F, Ruiz JR, Rey-López JP, Béghin L, Manios Y, Cuenca-García M, Plada M, Diethelm K, Kafatos A, Molnár D, Al-Tahan J, Moreno LA. Short sleep duration is associated with increased obesity markers in European adolescents: effect of physical activity and dietary habits. The HELENA study. Int $J$ Obes 2011; 35(10):1308-1317.

28. Wong MM, Robertson GC, Dyson RB. Prospective Relationship Between Poor Sleep and Substance-Related Problems in a National Sample of Adolescents. Alcohol Clin Exp Res 2015; 39(2):355-362.

29. Lina P, Rūta P. Chronobiological types, duration of sleeping and psycho-emotional condition of teenagers. Acta Med Litu 2016; 23(4):232-238.

30. Liu X, Zhang Q, Shang X. Meta-analysis of self-reported daytime napping and risk of cardiovascular or all-cause mortality. Med Sci Monitor 2015; 21:12691275 .

Article submitted 25/01/2018

Approved 20/06/2018

Final version submitted 22/06/2018 
